\title{
Comparison of Cardiac Rehabilitation Programs Combined with Relaxa- tion and Meditation Techniques on Reduction of Depression and Anxiety of Cardiovascular Patients
}

\author{
Mahdy Hassanzadeh Delui ${ }^{1, *}$, Maliheh Yari $^{2}$, Gholamreza khouyinezhad ${ }^{3}$, Maral Amini ${ }^{4}$ and \\ Mohammad Hosein Bayazi ${ }^{5}$
}

\author{
${ }^{1}$ Cardiovascular Research Center, Faculty of Medicine, Mashhad University of Medical Sciences, Mashhad, Iran \\ ${ }^{2}$ Department of Psychology, Torbat-e-Jaam Islamic Azad University, Torbat-e-Jaam Branch, Torbat-e-Jaam, Iran \\ ${ }^{3}$ Department of Educational sciences, Mashhad Islamic Azad University, Mashhad Branch, Mashhad, Iran \\ ${ }^{4}$ Young Researchers Club, Mashhad Islamic Azad University, Mashhad Branch, Mashhad, Iran \\ ${ }^{5}$ Department of Psychology, Torbat-e-Jaam Islamic Azad University, Torbat-e-Jaam Branch, Torbat-e-Jaam, Iran
}

\begin{abstract}
Cardiovascular disease (CVD) is a major cause of death in developed countries. Most cardiac rehabilitation programs include psychological interventions. The aim of this study was to determine the effectiveness of rehabilitation techniques in cardiac patients including psychological-physical interventions such as Meditation and Relaxation. We enrolled 45 patients with CVD and depression. The patients were allocated to 3 groups (Relaxation, Meditation and Control). There was a significant reduction on depression, systolic blood pressure and heart rate in the Meditation group compared with the control group. Our findings suggest that meditation techniques have better outcomes in cardiac patients for improving depression, reduction of systolic and diastolic blood pressure, and heart rate than relaxation techniques.
\end{abstract}

Keywords: Cardiac Rehabilitation, Diastolic blood pressure, Heart rate, Meditation, Relaxation, Systolic blood pressure.

\section{INTRODUCTION}

Cardiovascular disease (CVD) is a major cause of death in developed countries (1). At the beginning of the 20th century, less than $10 \%$ of world mortality was related to CVD. At the beginning of the 21 st century, almost half of the mortality in developed countries and $25 \%$ of death in developing countries is caused by CVD [1,2]. According to recent studies, the prevalence of coronary heart disease (CHD) and mortality rate in Iran has also increased [3]. Most of cardiovascular patients are unable to improve their health level and return to their full capabilities. Furthermore, different issues including absence from work, the high cost of medical procedures, medication and dysfunction are imposed both to society and patients [4].

Cardiac-rehabilitation programs were first developed from the 1960s $[5,6]$. The goals of cardiac rehabilitation and secondary prevention are to prevent disability, resulting from CHD, re-hospitalization and death from cardiac events. These techniques aimed to design appropriate interventions, to modify CHD risk factors to improve patient lifestyle [7]. Secondary prevention focuses on control of risk factors in the patients with established CHD [8].

*Address correspondence to this author at the Cardiovascular Research Center, Faculty of Medicine, Mashhad University of Medical Sciences, Mashhad, P.O. Box: 9176699199, Iran; Tel: +98-511-8430492;

Fax:+98-511-8430492; E-mail: hasanzadedaloeem@mums.ac.ir
The most important benefits of cardiac rehabilitation from the patients' insight, falls within the psychological part. Based on literature, after rehabilitation almost all of the psychological problems including anxiety, emotional stress, lack of self-confidence, depression, social isolation and patientsreported quality-of-life improve [9-12]. Besides, most of the cardiac rehabilitation programs, in many centers, include psychological interventions, particularly, stress management for depressed patients, as, it is reported that post-cardiac attack depression increases the mortality rate $[13,14]$.

Besides, depression is 3 times more common in patients after a heart attack than general population. It is estimated that 15 to $20 \%$ of heart attack victims qualify for diagnosis of major depressive disorder, and a far greater proportion experience increased levels of depressive symptoms [15]. Depression after a heart attack is bad not only because of the accompanying emotional distress and suffering; it also increases mortality rate with increased risk of having another heart attack compared with non-depressed [15]. Even tt has been reported that depression is a predictor of death in the first 6 months, following the heart attack [16].

Psychosocial interventions in standard cardiac rehabilitation programs might be able to clinically reduce the psychosocial pressure (such as depression and anxiety) and also the cardiovascular risk factors like high blood pressure and hyperlipidemia [17]. 
For the first time, Jakobson described relaxation techniques in 1929. In these techniques attempted to induce the physiological effects such as decreasing the heart rate, increasing peripheral blood flow, and neuromuscular stabilization, that are contrary to anxiety effects [18]. Relaxation techniques reduce the heart rate, blood pressure, and improve energy consumption, insomnia, headache and subsequent depression [19, 20].

Besides, meditation is the altered state of consciousness that achieves through meditation practice with proper training. These exercises consists control and regulation of breathing, major reduction of peripheral attention, Ignoring external stimulants, inserting Yoga modes and making mental images of a pleasant event or a particular symbol [21]. The purpose of meditation is to increase a person's ability to be relaxed, meanwhile dealing with stress situations and to obtain clear awareness or insight about nature of the experiences, away from the current emotional and cognitive distortions $[17,21]$.

Mounting evidence have consistently indicated that relaxation therapy is effective in alleviating anxiety and depressive moods [22-25]; reducing sympathetic-related manifestations on cardiovascular variables such as blood pressure [22], heart rate [23], and heart rate variability [26]; and lowering the frequency of angina attack and supraventricular tachycardia $[27,28]$ in patients with hypertension and coronary artery disease.

Earlier Studies have shown beneficial effects of Transcendental meditation (TM) on cardiovascular risk factors and quality of life $[29,30]$. TM program had positive impact on the treatment of hypertension in Africans Americans [3133]. Two randomized control studies of TM interventions in African Americans reported reductions in left ventricular mass and a regression of carotid atherosclerosis compared to controls [32-34].

The aim of this study was to hypothesize the effectiveness amount of rehabilitation techniques in cardiac patients including psychological-physical interventions such as meditation and muscle relaxation practices, to reduce depression and anxiety in cardiac patients, in addition to the exercise and diet regime and find the differences between them.

\section{MATERIAL AND METHODOLOGY}

The subjects of this quasi-experimental study were 45 patients with CVD and depression (18 female and 27 male), referred to Pasargad cardiac rehabilitation center in Mashhad, Iran. The patients were allocated in 3 groups randomly and 15 patients were enrolled in each group. Patient age, gender, literacy level and marital status were matched among the groups. The inclusion criteria were as follows: ages "between" 40-65 years old, at least primary education level, known CHD, and present depression. Depression was assessed by using Beck Depression questionnaire. These patients in both groups selected randomly among the records of registered patients of our center, not regarding the severity or extent of their disease to evaluate overall usability of interventions on the CHD patients.

In the first step, all the patients informed about of the study protocol. The Ethics Committee (of the Research
Council of Mashhad University of Medical sciences) approved the study protocol. All the patients filled in the informed consent form, prior to participation in the study.

Then we assessed depression and anxiety of the patients by Beck questionnaire and Zung Self-Rating Anxiety Scale (SAS) before the intervention [35, 36]. Case and control groups obtained equivalent scores in pre- and post-tests by taking Fisher test between average scores of 3 groups in pretest stage. Therefore, the depression and anxiety scores were matched in case and control groups. When the test is scored, a value of 0 to 3 is assigned for each answer and then the total score is compared to a key to determine the depression's severity. The standard cut-offs for Beck questionnaire are as follows:

- 0-9: indicates minimal depression

- 10-18: indicates mild depression

- 19-29: indicates moderate depression

- 30-63: indicates severe depression.

Higher total scores indicate more severe depressive symptoms. Also the total scores range for Zung Self-Rating Anxiety Scale (SAS) is from 20-80.

- 20-44 Normal Range

- 45-59 Mild to Moderate Anxiety Levels

- 60-74 Marked to Severe Anxiety Levels

- 75-80 Extreme Anxiety Levels

We held ten sessions of Jacobson's Progressive muscle relaxation (PMR) in the first group, and the second group was taught Mindfulness meditation techniques for ten sessions and the third group did not receive any trainings or intervention.

Each relaxation and meditation session lasted 20 and 25 min. All the patients in 2 intervention groups practiced related Techniques, after routine rehabilitation programs. Furthermore, they practiced their related Techniques 3 times at home with an educational compact disk, given to them. Trained nurses assessed and recorded blood pressure and heart rate of the patients at the beginning and the end of each session of rehabilitation. Also depression and anxiety were assessed at the end of tenth session. In addition, the posttreatment measures were conducted by individuals blinded to the study treatment conditions. The collected data were analyzed using Social Package for Social Statistical SPSS program version 10 . The One-way analysis and independent ttest was used to determine the difference between various variables and the P-Value was set as $<0.05$ for significance.

\section{STATISTICAL ANALYSIS}

Software of package for social statistics (SPSS) version 16.0 was used for statistical analysis. The descriptive data presented in table and as mean $\pm \mathrm{SD}$. The inferential statistical analysis conducted between three groups, by one-way ANOVA when normality of data approved, otherwise the parallel nonparametric test, Kruskal-Wallis was used. Posthoc techniques were used for comparison within groups, by using a Tukey test. Significant level for all measurements was $<0.05$. 


\section{RESULTS}

The subjects of this quasi-experimental study were 45 patients with CVD and depression (18 females and 27 males), whom were referred to Pasargad cardiac rehabilitation center in Mashhad, Iran. Age ranges of the patients were 40-65 years old and the literacy level of the patients varied between primary school up to higher education (undergraduate degree).

According to the results of Table $\mathbf{1}$, there was a significant reduction in pre- and post-scores of anxiety, depression, systolic blood pressure and heart rate in all three groups $(\mathrm{p}<$ 0.05 ) after rehabilitation. However, no significant difference was observed in reduction of diastolic blood pressure between groups $(\mathrm{p}=0.069)$.

\section{DEPRESSION AND ANXIETY IMPROVEMENT}

As demonstrated in Table 2, depression and anxiety scores in the relaxation group, compared with the control group, were not significantly different $(\mathrm{p}=0.496$ and $\mathrm{p}=$ 0.999). But there was a significant reduction in depression

Table 1. Pre- and Post-test Scores of Relaxation, Meditation and Control Groups

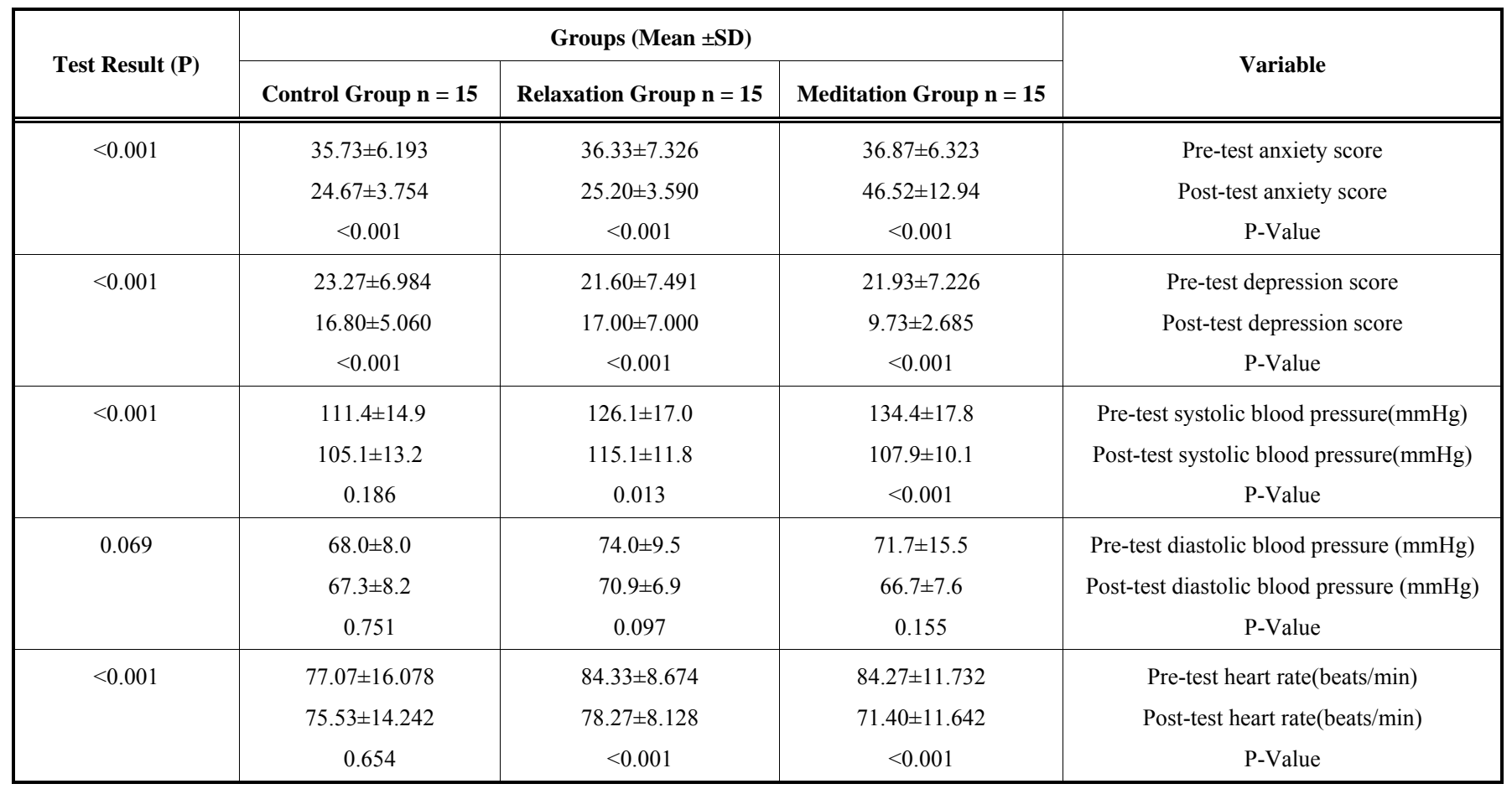

Table 2. Anxiety, Depression, Systolic Blood Pressure, Heart rate of Relaxation and Meditation Groups Compared with Control Group

\begin{tabular}{|c|c|c|c|c|}
\hline Test Result (P-Value) & Groups (Mean Difference \pm SE) & \multicolumn{3}{|c|}{ Variable } \\
\hline 0.27 & $3.07 \pm 1.95$ & Relaxation & \multirow{2}{*}{ Meditation } & \multirow{3}{*}{ Anxiety score } \\
\hline 0.25 & $3.13 \pm 1.95$ & control & & \\
\hline 0.999 & $3.13 \pm 1.95$ & control & Relaxation & \\
\hline$<0.001$ & $7.60 \pm 1.64$ & Relaxation & \multirow{2}{*}{ Meditation } & \multirow{3}{*}{ Depression score } \\
\hline 0.003 & $5.73 \pm 1.64$ & control & & \\
\hline 0.496 & $-1.87 \pm 1.64$ & control & Relaxation & \\
\hline 0.42 & $15.6 \pm 6.2$ & Relaxation & \multirow{2}{*}{ Meditation } & \multirow{3}{*}{$\begin{array}{l}\text { Systolic blood pres- } \\
\text { sure }(\mathrm{mmHg})\end{array}$} \\
\hline 0.006 & $20.2 \pm 6.2$ & control & & \\
\hline 0.742 & $4.6 \pm 6.2$ & control & Relaxation & \\
\hline 0.14 & $6.80 \pm 3.48$ & Relaxation & Meditation & \multirow{3}{*}{ Heart rate (beats/min) } \\
\hline 0.006 & $11.33 \pm 3.48$ & control & & \\
\hline 0.401 & $4.53 \pm 3.48$ & control & Relaxation & \\
\hline
\end{tabular}


scores, between meditation and control groups $(\mathrm{p}=0.003)$ while no difference in anxiety scores between meditation group and the control group observed $(\mathrm{p}=0.255)$.

\section{SYSTOLIC AND DIASTOLIC BLOOD PRESSURES}

According to the results there was no significant reduction in systolic and diastolic blood pressures, between relaxation group and the control group $(\mathrm{p}=0.742$ and $\mathrm{p}=$ 0.097) But according to the comparison of scores, relaxation training might be able to reduce systolic blood pressure dramatically (Table 2 ). There was a statically significant reduction in systolic blood pressure of the meditation group compared with control group $(\mathrm{p}=0.006)$ but no significant reduction was observed in diastolic blood pressure of them $(\mathrm{p}$ $=0.155)$.

\section{HEART RATE}

No significant difference was observed in heart rate of relaxation group compared with control group $(p=0.401)$, but according to the scores, relaxation training might be able to control the reduction of heart rate, to some extent (Table 2). In contrast, there was significant difference in heart rate of the meditation training group compared with control group $(\mathrm{p}=0.006)$.

\section{DISCUSSION}

The results of this study indicated that meditation techniques are more effective than relaxation techniques, in improvement of depression, reduction of systolic and diastolic blood pressure and heart rate.

Considering the difference averages in meditation group with control group, reached the conclusion that cardiac rehabilitation programs in the relaxation group might be effective in reducing depression, but it was not very impressive. Our results are consistent with those reported by Collins et al. 1997 [37] as they did not support the effectiveness of relaxation techniques on reducing symptoms of depression. The study of You et al. 2007[38] showed that muscle relaxation techniques have a moderate effect on depression. Similarly, in the study of Jolliffe et al. 2001 [39] any results based on the superiority of relaxation cardiac rehabilitation programs, on usual cardiac rehabilitation programs was not reported.

In contrast, in many other studies such as Jacobs et al. 2001 [40], van Dixhoorn et al. 2005 [41], Cowan et al 2001 [42], Rees et al. 2004 [43], Karlsson et al. 2003 [44], Hui et al. 2006 [45] relaxation techniques significantly reduced depression in CVD patients. These studies indicated that muscle relaxation techniques were significantly reduced depression and improved the patient lifestyle.

In the present study, anxiety was not significantly different in the relaxation and meditation groups compared with the control group. While, the previous studies revealed that anxiety was reduced in patients after discharge [7]. In Our study, patients were not anxious because the patients that referred to rehabilitation centers were in the recovering time, so it is clear that their anxiety was not significant.

According to the results, there was a significant reduction in depression between meditation and control groups. These findings are in agreement with previous literature that meditation exercises considered effective in reduction of depression in cardiac rehabilitation programs [46].

There was no significant reduction in systolic and diastolic blood pressure, between relaxation and the control group, which is different with other studies [47]. Also, there was no significant reduction in heart rate, between the relaxation and control groups that is inconsistent with Quiens and Rice et al. 1997 [37] findings.

Previously, it was assumed that diastolic pressure is a better indicator than systolic blood pressure, to assess the potential health risks. Even though, a recent long-term study has shown that high systolic blood pressure is not just equally but even more important [48]. In our study, there was a statistically significant reduction in systolic blood pressure of meditation group compared with the control group that is consistent with those reported by Anderson [49].

According to our results, there was significant reduction in heart rate of the meditation group compared with control group, and the same results are found by other studies [50].

Generally, it seems that cardiac rehabilitation along with meditation has better effects in reduction of depression, systolic and diastolic blood pressure and heart rate, so this study confirm usability of this technique in cardiac rehabilitation programs to promote physical and mental health of cardiac patients.

\section{CONCLUSIONS}

Our findings suggest that meditation techniques showed better outcomes in cardiac patients for reduction of systolic and diastolic blood pressure, heart rate and significant improvement of depression compared with relaxation techniques. Besides, we offer to evaluate this technique, in prolonged period, to assess its long term efficacy, in quality of life and well-being of CVD patients.

\section{CONFLICT OF INTEREST}

The authors confirm that this article content has no conflicts of interest.

\section{ACKNOWLEDGEMENTS}

None declared.

\section{REFERENCES}

[1] Murray CJ, Lopez AD. Mortality by cause for eight regions of the world: Global Burden of Disease Study. Lancet 1997; 349(9061): 1269-76.

[2] World Health Organization. Reducing risks, promoting healthy life. World Health Organization, ed. Ref Type: Report 2002.

[3] Bonita R. Stroke trends in Australia and New Zealand: mortality, morbidity, and risk factors. Ann Epidemiol 1993; 3: 529-33.

[4] Hassantash A. Caring before and after cardiac surgery. $1^{\text {st }}$ ed. Tehran: Ettalaat Publication 2000; pp: 12-3.

[5] Wenger N, Hellerstein HK, Blackburn H, Castranova SJ. Uncomplicated myocardial infarction: current physician practice in patient management. JAMA 1973; 224: 511-4.

[6] Hellerstein HK. Exercise therapy in coronary disease. Bull N Y Acad Med 1968; 44: 1028-47. 
[7] Ades PA. Cardiac Rehabilitation and Secondary Prevention of Coronary Heart Disease. N Engl J Med 2001; 345(12): 892-902.

[8] Rossouw JE, Lewis B, Rifkind BM. The value of lowering cholesterol after myocardial infarction. N Engl J Med 1990; 323: 1112-9.

[9] Ades PA, Pashkow FJ, Fletcher G, Pina IL, Zohman LR, Nestor JR. A controlled trial of cardiac rehabilitation in the home setting using electrocardiographic and voice transtelephonic monitoring. Am Heart J 2000; 139: 543-8.

[10] Ades PA, Maloney A, Savage P, Carhart RL Jr. Determinants of physical functioning in coronary patients: response to cardiac rehabilitation. Arch Intern Med 1999; 159: 2357-60.

[11] Linden W, Stossel C, Maurice J. Psychosocial interventions for patients with coronary artery disease: a meta-analysis. Arch Intern Med 1996; 156: 745-52. [Erratum, Arch Intern Med 1996; 156: 2302.

[12] Oldridge N, Guyatt G, Jones N, et al. Effects on quality of life with comprehensive rehabilitation after acute myocardial infarction. Am J Cardiol 1991; 67: 1084-9

[13] Frasure-Smith N, Lesperance F, Gravel G, et al. Social support, depression, and mortality during the first year after myocardial infarction. Circulation 2000; 101: 1919-24.

[14] Rosenman RH, Brand RJ, Jenkins D, Friedman M, Straus R, Wurm M. Coronary heart disease in Western Collaborative Group Study: final follow-up experience of 8 1/2 years. JAMA 1975; 233: 872-7.

[15] Williams RB. Depression after Heart Attack Why Should I Be Concerned About Depression after a Heart Attack? Circulation 2011; 123: e639-40.

[16] Gurung RAR. Health Psychology: A Cultural Approach. 2nd ed. USA: Thomson Wadsworth 2007.

[17] Fuster VR. Alexander WRA, Rourke O. Hurst's the Heart. $11^{\text {th }}$ ed. USA: Mc Graw-Hill Medical Publishing Division 2004.

[18] Sadock BJ, Kaplan HI, Ruiz P. Comprehensive text book of psychiatry. $7^{\text {th }}$ ed. USA: Wolters Kluwer Lippincott Williams and Wilkins 2000.

[19] Terathongkum S, Pickler RH. Relationships among heart rate variability, hypertension, and relaxation techniques. J Vasc Nurs 2004; 22: $78-82$

[20] Blumenthal JA, Jiang W, Babyak MA, et al. Stress management and exercise training in cardiac patients with myocardial ischemia Effects on prognosis and evaluation of mechanisms. Arch Intern Med 1997; 157: 2213-23.

[21] Collins JA, Rice VH. Effects of relaxation intervention in Phase II cardiac rehabilitation: replication and extension. Heart Lung 1997; 26: 31-44.

[22] Trzcieniecka-Green A, Steptoe A. The effects of stress management on the quality of life of patients following acute myocardial infarction or coronary artery bypass surgery. Eur Heart J 1996; 17: 1663- 70.

[23] Wilk C, Turkoski B. Progressive muscle relaxation in cardiac rehabilitation: a pilot study. Rehabil Nurs 2001; 26: 238-42.

[24] vanDixhoorn J. Cardiorespiratory effects of breathing and relaxation instruction in myocardial infarction patients. Biol Psychol 1998; $49: 123-35$

[25] Bundy C, Carroll D, Wallace L, Nagle R. Stress management and exercise training in chronic stable angina pectoris. Psychol Health 1998; 13: 147-55.

[26] Van Dixhoorn JJ, Duivenvoorden HJ. Effect of relaxation therapy on cardiac events after myocardial infarction: a 5-year follow-up study. J Cardiopulm Rehabil 1999; 19: 178-85.

[27] Barnes VA, Trieber FA, Davis H. Impact of transcendental meditation on cardiovascular function at rest and during acute stress in adolescents with high normal blood pressure. J Psychosom Res 2001; 51: 597-605.

[28] Wenneberg SR, Schneider RH, Walton KG, et al. A controlled study of the effects of the transcendental meditation program on cardiovascular reactivity and ambulatory blood pressure. Int J Neurosci 1997; 89: 15-28.
[29] Barnes V. Stress, stress reduction and hypertension in African Americans: an updated review. J Natl Med Assoc 1997; 89: 464-7.

[30] Alexander CN, Schneider RH, Staggers F, et al. Trial of stress reduction for hypertension in older African Americans: part II. Sex and risk subgroup analysis. Hypertension 1996; 28: 228-37.

[31] Schneider RH, Alexander CN, Staggers F, et al. Long-term effects of stress reduction on mortality in persons $\geq 55$ years of age systemic hypertension. Am J Cardiol 2005; 95: 1060-4.

[32] Castillo-Richmond A, Schneider RH, Alexander CN, et al. Effects of stress reduction on carotid atherosclerosis in hypertensive African Americans. Stroke 2000; 313: 568-73.

[33] Rainforth MV, Schneider RH, Nidich SI, Gaylord-King C, Salerno $\mathrm{JW}$, Anderson JW. Stress reduction programs in patients with elevated blood pressure: a systematic review and meta-analysis. Curr Hypertens Rep 2007, 9: 520-8.

[34] Ospina MB, Bond K, Karkhaneh M, et al. Clinical trials of meditation practices in health care: characteristics and quality. J Altern Complement Med 2008; 14: 1199-213.

[35] Beck AT, Ward CH, Mendelson M, Mock J, Erbaugh J. An inventory for measuring depression. Arch Gen Psychiatry 1961; 4: 56171 .

[36] Zung WW. A rating instrument for anxiety disorders. Psychosomatics 1971; 12(6): 371-9.

[37] Collins JA, Rice VH. Effects of relaxation intervention in phase II cardiac rehabilitation: replication and extension. Heart Lung 1997; 26: 31-44.

[38] Yu DS, Lee DT, Woo J. Effects of relaxation therapy on psychologic distress and symptom status in older Chinese patients with heart failure. J Psychosom Res 2007; 62: 427-37.

[39] Jolliffe JA, Rees K, Taylor RS, Thompson D, Oldridge N, Ebrahim $\mathrm{S}$. Exercise-based rehabilitation for coronary heart disease. Cochrane Database Syst Rev 2001; ( 1): CD001800.

[40] Jacobs GD. Clinical applications of the relaxation response and mind-body interventions. J Altern Complement Med 2001; 7 Suppl 1: S93-101.

[41] Van Dixhoorn J, White A. Relaxation therapy for rehabilitation and prevention in ischaemic heart disease: a systematic review and meta-analysis. Eur J Cardiovasc Prev Rehabil 2005; 12: 193-202.

[42] Cowan MJ, Pike KC, Budzynski HK. Psychosocial nursing therapy following sudden cardiac arrest: impact on two-year survival. Nurs Res 2001; 50: 68-76.

[43] Rees K, Bennett P, West R, Davey SG, Ebrahim S. Psychological interventions for coronary heart disease. Cochrane Database Syst Rev 2004; (2): CD002902.

[44] Karlsson MR, Edström-Plüss C, Held C, Henriksson P, Billing E, Wallén NH. Effects of expanded cardiac rehabilitation on psychosocial status in coronary artery disease with focus on type D characteristics. J Behav Med 2007; 30: 253-61.

[45] Hui PN, Wan M, Chan WK, Yung PM. An evaluation of two behavioral rehabilitation programs, qigong versus progressive relaxation, in improving the quality of life in cardiac patients. J Altern Complement Med 2006; 12: 373-8.

[46] Barth J, Schumacher M, Herrmann-Lingen C. Depression as a risk factor for mortality in patients with coronary heart disease: A Metaanalysis. Psychosom Med 2004; 66: 802-13.

[47] Najafian J, Gholestan Hashemi SM. A Study of the effect of relaxation and biofeedbackassisted relaxation on patients with mild hypertension. ARYA Atheroscler J 2006; 1: 178-82.

[48] J Stamler, Stamler R, Neaton JD. Blood Pressure, Systolic and Diastolic, and Cardiovascular Risks. Arch Intern Med 1993; 153: 598-615.

[49] Anderson JW, Liu C, Kryscio RJ. Blood pressure response to transcendental meditation: a meta-analysis. Am J Hypertens 2008; 21 : 310-6.

[50] Wallace RK. Physiological Effects of Transcendental Meditation. Science 1970; 167: 1751-4. 